\title{
Peningkatan Kualitas Tanah Bekas Tambang Pasir Melalui Penambahan Amelioran Biologis
}

\author{
Anne Nurbaity ${ }^{1}$, Anni Yuniarti ${ }^{1}$ dan Sungkono ${ }^{1}$ \\ ${ }^{1}$ Departemen Ilmu Tanah Fakultas Pertanian Universitas Padjadjaran \\ Jl. Raya Bandung Sumedang km.21 Jatinangor 45363 \\ Alamat korespondendsi: a.nurbaity@unpad.ac.id
}

\section{ABSTRACT \\ Improving soil quality from sand mining area by application of biological ameliorants}

Soil from disturbed mine sites render to be unfertile and have poor characteristics. One of the solutions to improve the soil and to rehabilitate the ecosystem is through application of biological amendments such as organic matter, soil microbes, and plant which known to be adaptive such as dragon fruit (Hylocereus costaricensis). This study was aimed at understanding the effects of arbuscular mycorrhizal (AM) fungi and organic matter on soil C-organic, soil N-total, soil C/N, and length of bud of dragon fruits grown on soil originated from sand mining, Sumedang, Indonesia under greenhouse condition. Different types of organic matter i.e. chicken manure, goat manure, cow manure and rabbit manure were applied. Results of experiment showed that application of manures and AMF was significantly improved soil C-organic content, $\mathrm{N}$-total, and $\mathrm{C} / \mathrm{N}$, as well as length of bud of dragon fruit plants. Planting soil from sand mine sites with dragon fruit combined with organic matter and mycorrhiza has potential as restoration tools on ecosystem of sand-mining areas.

Keywords: Sand-mine, Mycorrhiza, Manure, Dragon fruit

\begin{abstract}
ABSTRAK
Tanah pada lahan bekas tambang galian pasir memiliki tingkat kesuburan yang rendah. Salah satu upaya untuk meningkatkan kualitas tanah dan ekosistem di wilayah penambangan pasir adalah melalui aplikasi amelioran biologis berupa bahan organik, mikroba tanah, dan tanaman yang dikenal adaptif terhadap lahan berpasir, seperti buah naga (Hylocereus costaricensis). Tujuan dari penelitian ini adalah untuk mengetahui efek pemberian berbagai jenis pupuk kandang (PK: berasal dari kotoran ayam, kambing, sapi, dan kelinci) dan fungi mikoriza arbuskula (FMA) terhadap kandungan $\mathrm{C}$-organik, $\mathrm{N}$-total, $\mathrm{C} / \mathrm{N}$ tanah dan panjang tunas bibit buah naga super merah yang ditanam pada tanah bekas tambang pasir asal Sumedang, Indonesia pada kondisi rumah kaca. Hasil percobaan menunjukkan bahwa pemberikan pupuk kandang dan mikoriza meningkatkan kandungan $\mathrm{C}$-organik, $\mathrm{N}$-total, $\mathrm{C} / \mathrm{N}$ tanah dan panjang tunas bibit buah naga super merah secara nyata. Kombinasi PK sapi dengan FMA atau PK kelinci tanpa FMA menghasilkan tunas bibit buah naga terbaik. Penanaman buah naga di lahan bekas tambang pasir yang dikombinasikan dengan pupuk kandang dan mikroba tanah seperti fungi mikoriza memiliki potensi sebagai sarana untuk restorasi ekosistem di wilayah penambangan pasir.
\end{abstract}

Kata kunci: Tambang pasir galian C, Pupuk kandang, Mikoriza, Buah naga 


\section{PENDAHULUAN}

Potensi sumber daya alam berupa bahan tambang di Indonesia sangat besar, termasuk tambang galian pasir atau tambang golongan $\mathrm{C}$. Kegiatan penambangan pasir meliputi pekerjaan pembukaan lapisan penutup tanah, penggalian bahan tambang, hingga pengangkutan (Anto, 2008). Penambangan pasir yang dilakukan secara intensif telah mengakibatkan berbagai masalah yang sangat serius, terutama kerusakan lingkungan seperti berubahnya funsi lahan dan hilangnya lapisan tanah atas yang subur, sehingga kondisi lahan menjadi sangat tidak subur atau kritis (Dinas Pertanian Tanaman Pangan, 2011).

Tanah pasir bekas tambang memiliki tekstur yang kasar dan lepas, kapasitas serap air rendah, serta kandungan unsur hara dan bahan organik yang rendah, sehingga tanah ini tidak subur jika dijadikan media pertumbuhan tanaman (Abadi, 2009). Untuk mengatasi permasalah tersebut, diperlukan upaya perbaikan untuk mengembalikan kesuburan tanah dan pertumbuhan tanaman.

Salah satu alternatif yang dapat dilakukan untuk memulihkan tanah pada lahan bekas tambang pasir adalah melalui aplikasi teknologi biologis fitoremediasi berupa penanaman tanaman yang adaptif terhadap tanah berpasir. Sejalan dengan upaya tersebut, diperlukan terlebih dahulu perbaikan tanah melalui pemberian bahan organik seperti pupuk kandang dan fungi mikoriza arbuskula.

Buah naga (Hylocereus sp.) merupakan tanaman yang mampu beradaptasi dengan berbagai lingkungan tumbuh dan cuaca serta memiliki masa produksi yang panjang hingga 20 tahun (Hardjadinata, 2010). Di sekitar areal penambangan pasir di daerah Cimalaka Sumedang Indonesia, masyarakat sudah mulai menanam buah naga sebagai upaya restorasi lahan bekas tambang pasir. Karena tingkat kesuburan tanahnya yang rendah, maka perlu diberikan bahan organik antara lain pupuk kandang.

Pupuk kandang diperoleh dari kotoran padat dan cair hewan ternak, baik segar maupun yang telah melalui proses dekomposisi. Aplikasi pupuk kandang dapat meningkatkan kandungan unsur hara $\mathrm{N}, \mathrm{P}, \mathrm{K}, \mathrm{Ca}, \mathrm{Mg}$, dan $\mathrm{S}$, serta kandungan $\mathrm{C}$-organik, yang pada akhirnya dapat meningkatkan aktivitas mikroba tanah (Hartatik \& Widowati, 2008). Namun demikian, jenis hewan yang berbeda akan menghasilkan pupuk kandang dengan kandungan hara berbeda-beda pula. Oleh karenanya, perlu dicobakan berbagai jenis pupuk kandang dari berbagai hewan ternak seperti ayam, sapi, kambing, dan kelinci agar diperoleh hasil terbaik di dalam meningkatkan pertumbuhan buah naga.

Fungi mikoriza arbuskula (FMA), dikenal sebagai agen hayati yang mampu meningkatkan serapan hara dan air untuk tanaman (Nurbaity \& Mira, 2007), serta meningkatkan stabilitas agregat tanah melalui struktur hifa yang dibentuknya (Nurbaity, 2011). Fungi ini bersimbiosis dengan hampir 90\% jenis tanaman (Brundrett et al., 1996) sehingga dapat digunakan sebagai bagian dari upaya perbaikan lahan kritis (Musfal, 2010). Aplikasi FMA untuk upaya reklamasi lahan bekas tambang pasir masih belum banyak dilakukan, sehingga perlu dilakukan percobaan untuk mengkombinasikan berbagai jenis pupuk kandang dan FMA di dalam upaya perbaikan tanah dan tanaman buah naga di lahan bekas tambang pasir

Penelitian ini bertujuan untuk mengetahui peningkatan kualitas tanah yang diukur dari kandungan C-organik, $\mathrm{N}$ total, $\mathrm{C} / \mathrm{N}$ tanah dan panjang tunas bibit buah naga akibat pemberian berbagai jenis pupuk kandang dan FMA. Di samping itu diharapkan didapat kombinasi perlakuan terbaik dari jenis pupuk kandang dan FMA yang menghasilkan pertumbuhan tanaman buah naga terbaik.

\section{BAHAN DAN METODE}

Percobaan dilakukan di rumah kaca dan laboratorium Kesuburan Tanah dan Nutrisi Tanaman, serta Laboratoirum Biologi Tanah, Fakultas Pertanian Universitas Padjadjaran, Jatinangor, Sumedang. Tanah yang digunakan berasal dari areal bekas penambangan pasir Cimalaka Sumedang Jawa Barat dari kedalaman 0-20 cm, yang diklasifikasikan ke dalam ordo Entisol (Anto, 2008).

Tanaman buah naga yang dipakai berupa stek buah naga super merah $(30 \mathrm{~cm}$ dengan ujung runcing) dari petani di Cimalaka Sumedang, sedangkan pupuk kandang yang digunakan adalah pupuk kandang ayam, kambing, sapi dan kelinci dari masyarakat sekitar Sumedang. Kandungan hara tanah dan pupuk kandang disajikan pada Tabel 1.

Percobaan menggunakan Rancangan Acak Kelompok dengan 10 kombinasi perlakukan dan tiga ulangan. Perlakuan yang diberikan adalah A) kontrol, (B) FMA, (C) PK ayam, (D) PK ayam + 
FMA, (E) PK kambing, (F) PK kambing + FMA, (G) PK sapi, (H) PK sapi + FMA, (I) PK kelinci, (J) PK kelinci + FMA.

Tanah pasir dicampur dengan pupuk kandang dengan perbandingan 1:1 (w/w) dan dimasukkan ke dalam polibag berukuran $30 \mathrm{~cm} \times 30 \mathrm{~cm}$ dengan berat media tanam $20 \mathrm{~kg}$. Tanah diinkubasi terlebih dahulu selama tiga minggu. Inokulan FMA yang digunakan merupakan campuran berbagai jenis (Glomus, Acaulospora dan Gigaspora) yang berasal dari Laboratorium Biologi Tanah Unpad. Pemberian FMA (10 g/polibag dengan jumlah spora 120) dilakukan seminggu sebelum tanam pada media tanam yang telah disiapkan dalam polibag pada kedalaman $5 \mathrm{~cm}$ di bawah lubang tanam.

Tabel 1. Kandungan unsur hara tanah dari tambang pasir dan pupuk kandang yang digunakan dalam percobaan.

\begin{tabular}{|c|c|c|c|c|c|c|}
\hline Parameter & Metode & Tanah & PK Ayam & PK Kambing & PK Sapi & PK Kelinci \\
\hline $\mathrm{pH} \mathrm{H} \mathrm{H}_{2} \mathrm{O}$ & Potensiometri & 6,49 & 6,71 & 9,23 & 6,77 & 8,19 \\
\hline C-organik & Walkley and Black (\%) & 0,55 & 25,58 & 44,78 & 33,39 & 36,33 \\
\hline N-total & Kjeldahl (\%) & 0,11 & 1,19 & 1,55 & 1,65 & 1,70 \\
\hline $\mathrm{C} / \mathrm{N}$ & & 5 & 22 & 29 & 20 & 21 \\
\hline $\mathrm{P}_{2} \mathrm{O}_{5}$ Total & $\%$ & & 0,72 & 0,42 & 0,66 & 0,53 \\
\hline $\mathrm{K}_{2} \mathrm{O}$ Total & & & 0,77 & 0,74 & 0,14 & 0,35 \\
\hline $\mathrm{P}_{2} \mathrm{O}_{5}$ Tersedia & Bray I (mg/kg) & 3,42 & & & & \\
\hline $\mathrm{P}_{2} \mathrm{O}_{5}$ Potensial & $\mathrm{HCl} 25 \%(100 \mathrm{mg} / \mathrm{g})$ & 35,60 & & & & \\
\hline $\mathrm{K}_{2} \mathrm{O}$ Potensial & & 6,56 & & & & \\
\hline
\end{tabular}

Bibit buah naga dengan ujung diruncingkan dan telah dikeringudarakan selama tiga hari, ditanam pada lubang tanam, dengan posisi tegak. Penyiraman dilakukan seminggu sekali pada kapasitas lapang. Setelah tanaman mulai tinggi, dilakukan pengikatan pada tongkat ajir yang ditancapkan di dalam polibag bersama dengan bibit tanaman.

Parameter yang diukur berupa pertumbuhan (panjang dan diameter) tunas bibit naga dilakukan setiap minggu selama 13 minggu, dan kandungan Corganik, $\mathrm{N}$-total dan $\mathrm{C} / \mathrm{N}$ tanah dilakukan di awal dan pada 13 minggu setelah tanam (MST). Data dianalisis dengan Uji F dan Uji lanjut Scott Knott pada taraf $5 \%$.

\section{HASIL DAN PEMBAHASAN}

\section{Kandungan C-organik tanah}

Pemberian pupuk kandang meningkatkan kandungan C-organik tanah secara nyata (Tabel 2). Jenis PK kambing menghasilkan kandungan Corganik tertinggi (6.47\%), diikuti PK sapi, PK ayam, dan PK kelinci. Hal ini sesuai dengan hasil analisis awal PK, bahwa PK kambing memiliki kandungan C-organik yang tertinggi (44,78\%).

Jika dibandingkan dengan perlakuan yang diberi FMA, tanah pasir yang tidak diberi FMA memiliki kandungan C-organik yang lebih tinggi. Corganik merupakan penyusun utama bahan organik. Di dalam tanah, FMA menggunakan bahan organik sebagai sumber $\mathrm{C}$ untuk melangsungkan metabolisme dan kehidupannya (Brundrett et al., 1996). Pada penelitian ini, karena pengukuran baru dilakukan sampai dengan minggu ke-13, dan sesuai siklusnya FMA baru memulai perkembangannya, maka FMA menggunakan bahan organik dari pupuk kandang yang diberikan sebagai sumber energi untuk pertumbuhan dan perkembangannya, sehingga C-organik yang diberi FMA lebih rendah dibandingkan dengan tanpa FMA. Hal ini sesuai dengan pendapat Wong et al. (2004) yang menyatakan bahwa ketersediaan $\mathrm{C}$ akan berkurang sejalan dengan proses dekomposisi dan $\mathrm{C}$ tersebut merupakan sumber substrat bagi mikroba tanah.

Pupuk kandang yang digunakan dalam percobaan ini memiliki rasio $\mathrm{C} / \mathrm{N}$ yang relatif masih tinggi (20-29) dibandingkan dengan $\mathrm{C} / \mathrm{N}$ tanah (5). Menurut Douds et al. (1997) kompos dengan C/N rasio yang rendah diperlukan untuk mendukung perkembangan simbiosis fungi MA.

\section{Kandungan N-total tanah}

Kandungan $\mathrm{N}$-total tanah pasir yang diberi pupuk kandang meningkat secara nyata (Tabel 2). 
Jenis PK kambing yang diberikan bersama dengan FMA menghasilkan kandungan $\mathrm{N}$-organik tertinggi (0.97\%), diikuti PK sapi, PK ayam, dan PK kelinci. Walaupun kandungan N-organik PK awal yang tertinggi dimiliki oleh $\mathrm{PK}$ kelinci, tetapi pada percobaan ini PK kambing memiliki N-organik tertinggi. Hal ini berkaitan erat dengan kandungan C-organik seperti dibahas sebelumnya. Berbeda dengan pengaruh perlakuan terhadap kandungan Corganik, perlakuan yang diberi FMA memiliki kandungan N-organik yang lebih tinggi dibandingkan tanpa diberi FMA.
Menurut Musfal (2010), disamping mampu meningkatkan kandungan $\mathrm{P}$ dalam tanah, FMA juga mampu meningkatkan kandungan $\mathrm{N}$ dalam tanah.Sumber utama $\mathrm{N}$ juga bahan organik, yang kemudian akan mengalami proses mineralisasi yaitu konversi $\mathrm{N}$ oleh mikroba dari $\mathrm{N}$-organik menjadi $\mathrm{N}$ anorganik. Oleh karena itu, pemberian pupuk kandang mampu meningkatkan proses dekomposisi oleh mikroba yang pada akhirnya akan meningkatkan kandungan $\mathrm{N}$ dalam tanah (Douds et al., 1997).

Tabel 2. Pengaruh jenis pupuk kandang dan fungi mikoriza arbuskula terhadap kandungan C-organik (\%), $\mathrm{N}-$ total (\%) dan C/N tanah.

\begin{tabular}{lccc}
\hline \multicolumn{1}{c}{ Perlakuan } & C-organik (\%) & N-total (\%) & $\mathrm{C} / \mathrm{N}$ \\
\hline Kontrol & $0,12 \mathrm{a}$ & $0,01 \mathrm{a}$ & $12 \mathrm{f}$ \\
Mikoriza & $0,17 \mathrm{~b}$ & $0,02 \mathrm{a}$ & $9 \mathrm{e}$ \\
PKA - mikoriza & $5,77 \mathrm{f}$ & $0,75 \mathrm{~d}$ & $8 \mathrm{~d}$ \\
PKA + mikoriza & $5,65 \mathrm{e}$ & $0,79 \mathrm{e}$ & $7 \mathrm{c}$ \\
PKK - mikoriza & $6,47 \mathrm{j}$ & $0,84 \mathrm{f}$ & $8 \mathrm{~d}$ \\
PKK + mikoriza & $6,34 \mathrm{~h}$ & $0,97 \mathrm{~h}$ & $8 \mathrm{~d}$ \\
PKS - mikoriza & $6,40 \mathrm{i}$ & $0,84 \mathrm{f}$ & $7 \mathrm{c}$ \\
PKS + mikoriza & $6,28 \mathrm{~g}$ & $0,87 \mathrm{~g}$ & $6 \mathrm{~b}$ \\
PKKl - mikoriza & $2,75 \mathrm{~d}$ & $0,48 \mathrm{~b}$ & $5 \mathrm{a}$ \\
PKKl + mikoriza & $2,67 \mathrm{c}$ & $0,50 \mathrm{c}$ & \\
\hline
\end{tabular}

Keterangan:

- $\quad \mathrm{PKA}=\mathrm{PK}$ ayam, $\mathrm{PKK}=\mathrm{PK}$ kambing, $\mathrm{PKS}=\mathrm{PK}$ sapi, $\mathrm{PKKl}=\mathrm{PK}$ kelinci.

- Angka-angka yang diikuti huruf yang sama tidak berbeda nyata (Scott Knott 5\%)

\section{Rasio C/N tanah}

Rasio $\mathrm{C} / \mathrm{N}$ tanah sangat dipengaruhi oleh pemberian pupuk kandang dan FMA (Tabel 2). Hasil akhir pengukuran $\mathrm{C} / \mathrm{N}$ tanah menunjukkan bahwa PK kambing, sapi, dan ayam memiliki $\mathrm{C} / \mathrm{N}$ yang sama (6-7) dan lebih tinggi daripada PK kelinci (56). Jika dihubungkan dengan kandungan C-organik tanah, nilai C/N PK kelinci menunjukkan telah terjadinya proses dekomposisi yang lebih lanjut. Nilai C/N yang rendah tersebut mendekati nilai $\mathrm{C} / \mathrm{N}$ tanah (Utami, 2009).

Pada tanah yang tidak diberi pupuk kandang, pemberian FMA nyata menurunkan $\mathrm{C} / \mathrm{N}$ rasio tanah sebesar 33\% (dari 12 menjadi 9). Hal ini menunjukkan pula bahwa FMA berkontribusi terhadap peningkatan C-organik dan $\mathrm{N}$-organik tanah. C-organik meningkat, karena fungi itu sendiri memiliki hifa dan komponen organi tubuhnya yang mati juga menjadi sumber $C$ dan FMA memproduksi enzim yang memungkinkan mereka mengakses $\mathrm{C}, \mathrm{N}$, dan $\mathrm{P}$ dari sumber bahan organik di dalam tanah (Dighton, 1991).

\section{Panjang tunas bibit buah naga}

Pemberian pupuk kandang dan FMA mempengaruhi secara nyata pertumbuhan tunas bibit buah naga (Tabel 3). Perlakuan yang memberikan panjang tunas tertinggi adalah perlakuan PK kelinci tanpa FMA. Walaupun demikian, secara umum, pemberian FMA jika dikombinasikan dengan PK selain kelinci (yaitu kambing, ayam dan sapi) selalu memberikan hasil yang lebih tinggi. Pengaruh yang sangat nyata adalah pada perlakuan PK sapi.

Nilai yang tinggi terdapat pada pemberian pupuk kandang kelinci tanpa FMA dan pemberian pupuk kandang sapi yang dikombinasikan dengan FMA (berturut-turut 89,5 cm dan $85,1 \mathrm{~cm}$ ). Pada dua perlakuan ini memiliki nilai berbeda tetapi tidak berbeda nyata sehingga merupakan panjang tertinggi dibandingkan perlakuan yang lain. 
Aplikasi FMA pada pemberian pupuk kandang ayam, kambing, dan sapi pada tanah pasir mengalami peningkatan, namun pada pupuk kandang ayam tidak berbeda nyata dengan tanpa FMA dan kontrol. Hal ini disebabkan karena pada kombinasi pupuk kandang ayam memiliki media yang sangat lembab sehingga pertambahan panjang tunas menjadi terhambat. Adapun pada pemberian pupuk kandang kambing tidak berbeda nyata antara pemberian FMA dengan tanpa FMA. Pemberian
FMA pada pupuk kandang sapi memberikan pengaruh yang nyata dan meningkatkan panjang tunas hingga $42 \%$ dibandingkan dengan tanpa FMA yang memiliki panjang tunas $60 \mathrm{~cm}$ menjadi 85,1 $\mathrm{cm}$. Kemudian pada pemberian pupuk kandang kelinci, perlakuan tanpa FMA memiliki panjang tunas lebih tinggi dengan nilai $89,5 \mathrm{~cm}$ dan berbeda nyata dibandingkan dengan perlakuan menggunakan FMA yang mengalami penurunan hingga 32\% menjadi $68 \mathrm{~cm}$.

Tabel 3. Pengaruh jenis pupuk kandang dan fungi mikoriza arbuskula terhadap panjang tunas bibit buah naga $(\mathrm{cm})$.

\begin{tabular}{|c|c|}
\hline Perlakuan & Panjang tunas $(\mathrm{cm})$ \\
\hline Kontrol & $22,1 \mathrm{a}$ \\
\hline Mikoriza & 19,6 a \\
\hline PKA - mikoriza & 17,9 a \\
\hline PKA + mikoriza & 21,7 a \\
\hline PKK - mikoriza & $49,9 \mathrm{~b}$ \\
\hline PKK + mikoriza & $65,3 \mathrm{~b}$ \\
\hline PKS - mikoriza & $60,0 \mathrm{~b}$ \\
\hline PKS + mikoriza & $85,1 \mathrm{c}$ \\
\hline PKKl - mikoriza & $89,5 \mathrm{c}$ \\
\hline PKKl + mikoriza & $68,0 \mathrm{~b}$ \\
\hline
\end{tabular}

Keterangan:

- $\quad \mathrm{PKA}=\mathrm{PK}$ ayam, $\mathrm{PKK}=\mathrm{PK}$ kambing, $\mathrm{PKS}=\mathrm{PK}$ sapi, $\mathrm{PKKl}=\mathrm{PK}$ kelinci.

- Angka-angka yang diikuti huruf yang sama tidak berbeda nyata (Scott Knott 5\%)

Jika dikaitkan dengan parameter tanah yang diukur, yaitu $\mathrm{C}$ organik, $\mathrm{N}$ total dan $\mathrm{C} / \mathrm{N}$ rasio tanah, maka pengaruh pupuk kandang kelinci yang memberikan pertumbuhan terbaik ini, berkaitan erat dengan nilai $\mathrm{C} / \mathrm{N}$ rasionya yang terendah atau telah mengalami degradasi. Bahan organik yang telah mengalami degradasi akan mempengaruhi ketersediaan unsur hara yang siap diserap oleh tanaman (Sutedjo, 2008).

\section{SIMPULAN}

1. Jenis pupuk kandang menentukan kandungan $\mathrm{C}$ organik tanah, $\mathrm{N}$ total tanah maupun $\mathrm{C} / \mathrm{N}$ rasio tanah yang pada akhirnya mempengaruhi ketersediaan hara dan pertumbuhan tanaman.

2. Fungi mikoriza arbuskula berperan di dalam peningkatan $\mathrm{N}$ total tanah dan penurunan $\mathrm{C} / \mathrm{N}$ rasio tanah.

3. Pemberian bahan organik berupa pupuk kandang dan fungi mikoriza arbuskula memberikan pengaruh yang nyata terhadap kandungan C-organik tanah, N-total tanah, $\mathrm{C} / \mathrm{N}$ rasio tanah, dan pertumbuhan tunas bibit buah naga yang ditanam pada tanah bekas tambang pasir.

\section{DAFTAR PUSTAKA}

Abadi, KM. 2009. Kondisi fisik, kimia, dan biologi tanah pasca reklamasi lahan agroforestri di area pertambangan bahan galian $\mathrm{C}$ kecamatan Astanajapura kabupaten Cirebon provinsi Jawa Barat. Departemen Silvikultur, Fakultas Kehutanan Institut Pertanian Bogor. Bogor.

Anto, G. 2008. Pengaruh penambangan pasir terhadap kualitas lahan di kecamatan Cimalaka kabupaten Sumedang. Pendidikan Geografi Universitas Pendidikan Indonesia. Bandung.

Brundrett, M, N Bougher, RW Bell, and TJ Hatton. 1996. Working with Mycorrhizas in Forestry and Agriculture. ACIAR. 
Canberra.

Dighton, J. 1991. Acquisition of nutrients from organic resourced by mycorrhizal autotrophic plants. Experientia 47:362-369.

Dinas Pertanian Tanaman Pangan. 2011. Rumah kompos untuk memperbaiki kesuburan lahan bekas tambang pasir Jawa Barat. http://www.disperta.jabarprov.go.id (diakses 14 Mei 2012).

Douds Jr., DD, L Galvez, M Franke-Snyder, C Reider and LE Drinkwater. 1997. Effect of compost addition and crop rotation point upon VAM fungi. Agriculture, Ecosystem and Environment 65:257-266.

Hardjadinata, S. 2010. Budidaya Buah Naga Super Red Secara Organik. Penebar Swadaya. Jakarta.

Hartatik, W dan LR Widowati. 2008. Pupuk kandang. Laporan proyek penelitian program pengembangan agribisnis. Balai Penelitian Tanah. Bogor.

Musfal. 2010. Potensi cendawan mikoriza arbuskula untuk meningkatkan hasil tanaman jagung. Balai Pengkajian Teknologi Pertanian Sumatera Utara.
Nurbaity, A. 2011. Mikoriza pembantu istimewa tanaman. Pikiran Rakyat 03/03/2011 h. 24. Bandung.

Nurbaity, A. dan Mira. 2007. Efisiensi penggunaan air, benefit dan cost tanaman jagung bermikoriza yang mengalami cekaman air. Prosiding seminar peran biotkenologi dalam rehabilitasi lahan kritis di tatar Sunda. Fakultas Pertanian Universitas Padjadjaran. Bandung.

Sutedjo, MM. 2008. Pupuk dan Cara Pemupukan. Rineka cipta, Jakarta.

Utami, NH. 2009. Kajian sifat fisik, sifat kimia, dan sifat biologi tanah bekas tambang galian $\mathrm{C}$ pada tiga penutupan tanah (studi kasus di desa Gumulung Tonggoh, kecamatan Astanajapura, kabupaten Cirebon Jawa Barat). Departemen Silvikultur, Institut Pertanian Bogor, Bogor.

Wong, VNL, RSB Greene, B Murphy, and R Dalal. 2004. The effects of salinity and sodicity on soil carbon turnover. Proceeding of $3^{\text {rd }}$ Australian New Zealand Soils Conference. 5-9 December 2004. The University of Sydney. Australia. 